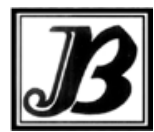

J. Bio-Sci. 28: 87-93, 2020

ISSN 1023-8654 http://www.banglajol.info/index.php/JBS/index DOI: https://doi.org/10.3329/jbs.v28i0.44714

\title{
APPLICATION OF PLANT EXTRACTS FOR PEST MANAGEMENT IN TEA: A STUDY ON TEA LEAF'S THRIPS, SCIRTOTHRIPS BISPINOSUS
}

\author{
MAK Azad ${ }^{*}$, I Ahmad ${ }^{1}$ and A Mainuddin ${ }^{2}$ \\ ${ }^{1}$ Department of Food Engineering and Tea Technology, Shahjalal University of Science \& Technology, Sylhet \\ 3114, Bangladesh \\ ${ }^{2}$ Bangladesh Tea Research Institute, Moulvibazar, Sylhet, Bangladesh
}

\begin{abstract}
Medicinal plant extract contains bioactive molecules and these molecules are benefited to mitigate, eradicate or cure diseases. In advent to search for new medicinally important plant, the current paper deals to select the most effective and promising plants which are suitable for controlling tea leaf's thrips (Scirtothrips bispinosus) based on extracts concentration and death affect over time. To fulfill the specific objectives, five medicinal plants extracts viz. Ipomoea crassicaulis, Lantana camara, Ipomoea hederaceaa, Glycosmis arborea, and Justicia gendarussa had been used with four different concentrations. From statistical analysis using One-way ANOVA and post hoc test, it was found that Ipomoea crassicaulis and Lantana camara are the most promising of all the experimented plants extracts based on both time and concentration. In the study, average mortality was found $0.47,1.67$, 1.93 and 2.53 for concentration of $1 \%, 5 \%, 10 \%$ and $15 \%$ respectively. Analysis based on different concentrations reveals that average mortality of thrips increases significantly with the increase of concentrations. Coefficient of variance was found minimum for Ipomoea crassicaulis and Lantana camara plants with range of 5.44 to 6.71 based on time and concentration. So, it could be concluded that these two plants are the most effective plants for controlling the tea thrips. For the other plants, ranks were found as Ipomoea hederaceaa, Glycosmis arborea and Justicia gendarussa respectively as well.
\end{abstract}

Key words: Extracts, Mortality, Plant, Post hoc test, Thrips

\section{Introduction}

Tea is one of the most consumed non-alcoholic as well as medicinal beverages in the world. At present, more than 58 countries around the world produce tea, while Bangladesh is now ranked $10^{\text {th }}$ position amongst the tea growing countries. Bangladesh Tea Board (BTB) reported that in 2017 production was 78.95 million $\mathrm{kg}$ while export was only 2.56 million $\mathrm{kg}(\mathrm{m} \mathrm{kg})$. Total internal consumption of tea product has been increased more than two times from 2001 to 2019 (from $36.96 \mathrm{~m} \mathrm{~kg}$ in 2001 to $85.93 \mathrm{~m} \mathrm{~kg}$ in 2019) in Bangladesh but production rate is not up-to the mark as compared to facility of technology. Tea plants are subjected to the attack of insects, mites and nematode pests (Paul et al. 2017). All parts of the plant (leaf, stem, root, flower and seed) are fed upon by at least one pest species. About $15 \%$ of tea production could be lost per year by various pests particularly insects, mites and nematodes if adequate control measures are not taken (Mamun et al. 2016). Moreover, production losses to extent of 50\% or more might be inflicted by the advent of an epidemic or outbreak of specific pests in a particular season or tea estate. Globally, 1031

*Author for correspondence: akazadt68@gmail.com 
species of arthropods are associated with tea monoculture (Hazarika et al. 2009) and the tea plant is subjected to attack by at least 250 insect species and 380 fungal pathogens. So far, 25 insect, four mites and 10 nematode species of tea related species had been recorded in Bangladesh (Sana 1989, Ahmed 2005). Due to climate change, pest infestation is increasing as well as pest status is changing (Noori et al. 2016). Besides, deforestation is resulting in the migration of forest pest to tea ecosystem (Antony et al. 2012). Natural bio-control agents play an important role to regulate the pest population in tea ecosystem. Existence of more than one hundred species of indigenous natural bio-control agents of tea pests including predators, parasites, parasitoids were recorded from the tea ecosystem (Borthakur et al. 2010).

The increasing awareness of negative effects of synthetic pesticide on human and animal health and the agro-ecosystem, research efforts on alternative and more environmentally friendly methods of controlling pests and diseases have proliferated (Zhou et al. 2019, Hagstrum and Athanassiou 2019). Usage of extract from plants containing natural anti-pest compounds for pest control is considered to be one of the desirable methods for plant protection in agriculture (Kim et al. 2003). In recent past, several plant species had been screened for anti-pest activity and extracts/purified compounds from these plants were found to have a broad spectrum of anti-pest activity (Grayer and Harborne 1994). Different types of microbial agent are being capable to protect leaf and stem damages of tea such as Trichoderma harzianum, Bacillus subtilis and pseudomonas fluorescence. Several higher plants and their constituents have shown success in pest and disease control (Ashrafuzzaman et al. 2011) and proved to be harmless and non-phytotoxic unlike chemical pesticides. Considering the above evidences, the present study was undertaken an in-vitro approach for finding out the suitable plants through application of plants extracts against Scirtothrips bispinosus (tea leaf's thrips) which could be effective to control the impact of the thrips naturally. The output of the study could be helpful to provide information regarding plant-insect interaction and to predict suitable techniques for controlling pests.

\section{Materials and Methods}

\section{Study area}

In this study, the basic element was tea leaves which were infected by thrips insects. These infected leaves were collected from three different tea gardens viz. Habibnagar Tea Estate, Khan Tea Garden (Sylhet district) and Baraoora Tea Estate (Moulvibazar district) located in the North-East of Bangladesh. Climate of this region is considered to be sub-tropical monsoon with three distinct seasons: pre-monsoon season (February to April), monsoon season (May to August) and winter season (September to October). This region experiences dry weather condition from November to April while the rainy season continues from May to October. Above $80 \%$ of annual rainfall is obtained during June to September. It was observed that about $1400 \mathrm{~mm}$ of annual rainfall is a critical limit and the monthly mean temperature is between $18.33^{\circ} \mathrm{C}$ to $29.44^{\circ} \mathrm{C}$ seem unfavorable for tea production in Bangladesh (Ahmed 2005, Sana 1989). Soil is highly weathered and extremely acidic with low fertility in this region. 


\section{Sample collection}

The thrips affected tea leaves were collected from three different sampling area which was named as replication. At the same time, five types of plants extracts had been used in four different concentrations: $1 \%$, $5 \%, 10 \%$ and $15 \%$. The plants were collected randomly from different places of Bangladesh. So, the total 60 samples (thrips affected leaves) were used in this study.

\section{Data recording and statistical analysis}

The laboratory work was carried out at Department of Forestry and Tea Technology, Shahjalal University of Science and Technology, Sylhet, Bangladesh from February, 2019 to April, 2019. The plant's leaves were used to get the essence of tree using $50 \%$ alcohol and used it on the tea leaves in different concentrations. Using in vitro method, $5 \mathrm{ml}$ essence of trees was used for each sample. Data analysis was carried out using analysis of variance (ANOVA). One-way ANOVA test is a widely used parametric test that is used to determine whether three or more groups have the same means. This test relies on the assumption that mortality of thrips have normal distribution and that the variances for all the groups are similar assumption had been satisfied. From the one-way ANOVA test, it was found that p-value has significant difference on mean time limit in hour to death affect for both plants and solution. Post hoc tests were applied to find out the significantly different pairs.

\section{Results and Discussion}

\section{Mortality of Thrips}

From results, it was found that mortality of thrips was different from plants to plants, concentration to concentration and time to time. In this study, five plants extracts had been used for the experimental work on thrips affected tea. The plants were Ipomoea crassicaulis, Ipomoea hederaceaa, Lantana camara, Glycosmis arborea and Justicia gendarussa. Fig. 2a illustrates average mortality of thrips within 24 hours depending on different plants extracts. The analysis revealed that Ipomoea crassicaulis had the maximum death effect (2.67). Ipomoea hederaceaa, Glycosmis arborea and Justicia gendarussa had lower than overall average mortality rate (1.90) which ranges from 1.67 to 1.83 (Fig. 2a).

Analysis based on different concentrations revealed that average mortality of thrips increased significantly with increase of concentrations (Fig. 2b). In this study, four different concentrations of plants extract (1\%, $5 \%$, $10 \%$ and $15 \%$ ) had been used to quantify the death affect against tea thrips. The coefficient of determination value (R-squared) explains that regression line fits well and any prediction or estimation made by the regression line may be accepted. Hence, average mortality of thrips also might be increased for $20 \%$ concentration of plants extracts. The study found that there had a differential result based on time effect on the mortality of thrips (Fig. 2c). A fact was that none of the five plants had any impact on the mortality of thrips within 6 hours. But maximum mortality rate of thrips was found within six to twelve hours. The study also revealed that the plants extracts were able to impact on mortality of thrips within 18 hours as average mortality rate decreased for the next six hours (from 18 to 24 hours) significantly. 

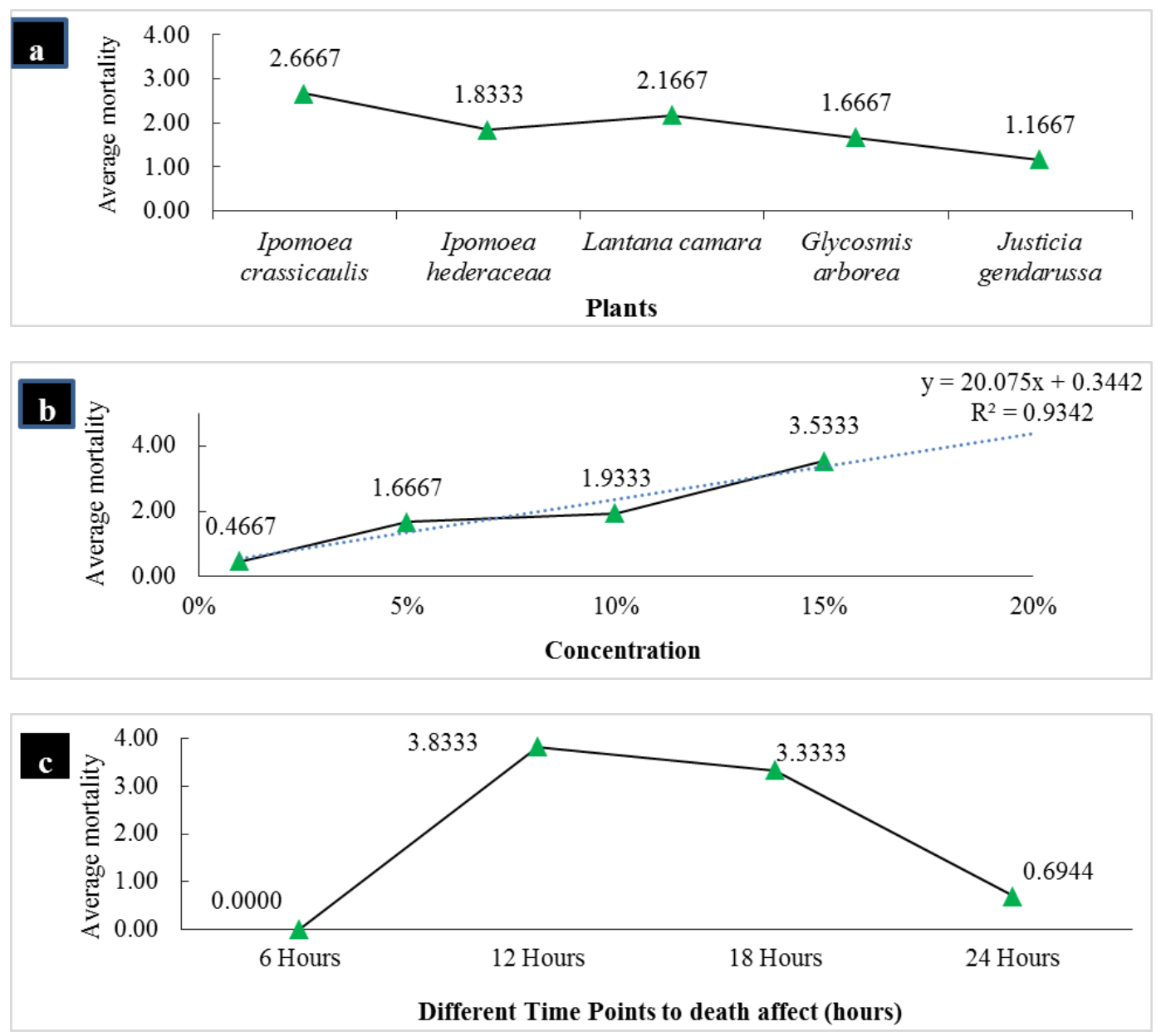

Fig. 2. Average mortality of thrips. a) Plants extracts, b) Concentration of plants essences and c) Time to death affect.

\section{Effect of time to thrips death}

In the study, it was determined and compared the efficacy of individual plants extracts against tea thrips on the experimental results obtained, to select the most effective and promising plant suitable for the development of natural pesticides. Table 2 illustrates the post hoc test result on time affect to tea thrips death affect against different plants extracts. From analysis, it was found that the number of tea thrips death differs from time limit and plants species. In the study, no death affect was found within first six hours. At the same time, it was found that Justicia gendarussa had no death effect on thrips up to 18 hours and upto 12 hours for Glycosmis arborea. From the mean standard deviation value, it is found that there is significant death affect relation between the plant pair of Ipomoea crassicaulis versus Ipomoea hederaceaa, Ipomoea hederaceaa versus Glycosmis arborea for the maximum time period of 12 hours. For the maximum time period of 18 
hours, this relation was found between the plants of Ipomoea crassicaulis vs Ipomoea hederaceaa and 4, Ipomoea hederaceaa vs Lantana camara and 4 , and for the maximum time period of 24 hours, the relation is found between Ipomoea crassicaulis vs Glycosmis arborea and Justicia gendarussa, Ipomoea hederaceaa vs Glycosmis arborea and Justicia gendarussa, Lantana camara vs Glycosmis arborea and Justicia gendarussa, and Glycosmis arborea vs Justicia gendarussa as well. Co-efficient of Variance was calculated based on maximum time limit (up to 24 hours) to select and ranking the most effective and promising plant depending on the time of death affect (Table 2). The result signifies that Ipomoea crassicaulis had the minimum CV value (5.4) and Ipomoea crassicaulis, Ipomoea hederaceaa, Glycosmis arborea, Justicia gendarussa respectively. So, Ipomoea crassicaulis extracts was found to be the most promising plant depending on the time of death affect.

Table 2. Post Hoc test result of different plants extracts to control tea thrips based on time

\begin{tabular}{ccccccc}
\hline \multirow{5}{*}{ Plant name } & \multicolumn{5}{c}{ Maximum time limit (hours) to death affect } \\
\cline { 2 - 6 } & $6 \mathrm{~h}$ & $12 \mathrm{~h}$ & $18 \mathrm{~h}$ & $24 \mathrm{~h}$ \\
\hline (N = No. of deaths) & Mean $\pm \mathrm{SD}$ & Mean $\pm \mathrm{SD}$ & Mean $\pm \mathrm{SD}$ & Mean $\pm \mathrm{SD}$ & $\mathrm{CV}$ & Ranking \\
\hline Ipomoea crassicaulis & $0.00 \pm 0.00$ & $8.33 \pm 2.00 \mathrm{a}$ & $8.33 \pm 2.00 \mathrm{a}$ & $10.67 \pm 0.58 \mathrm{a}$ & 5.44 & 1 \\
Ipomoea hederaceaa & $0.00 \pm 0.00$ & $7.33 \pm 0.58 \mathrm{ab}$ & $7.33 \pm 0.58 \mathrm{ab}$ & $7.33 \pm 0.50 \mathrm{~b}$ & 6.82 & 3 \\
Lantana camara & $0.00 \pm 0.00$ & $4.67 \pm 1.21 \mathrm{~b}$ & $7.00 \pm 1.41 \mathrm{~b}$ & $8.50 \pm 0.57 \mathrm{ab}$ & 6.71 & 2 \\
Glycosmis arborea & $0.00 \pm 0.00$ & $0.00 \pm 0.00$ & $4.33 \pm 0.58 \mathrm{ab}$ & $5.22 \pm 1.20 \mathrm{c}$ & 22.99 & 4 \\
Justicia gendarussa & $0.00 \pm 0.00$ & $0.00 \pm 0.00$ & $0.00 \pm 0.00$ & $2.27 \pm 2.33 \mathrm{~d}$ & 102.64 & 5 \\
\hline Total & $0.00 \pm 0.00$ & $6.94 \pm 2.29$ & $5.00 \pm 1.79$ & $5.67 \pm 3.07$ & 54.14 & -
\end{tabular}

Means within a column followed by the same letters are not statistically significantly different based on

Tukey's Post Hoc (Liu et al. 2015) test (at $p=0.05$ ).

\section{Effect of concentration to thrips death}

From the study, it was also tried to determine and compare the efficacy of individual plants extracts against tea thrips to select the most effective plant suitable for using as natural pesticides based on plants extracts concentrations. Four different concentrations of plants extras had been used to fulfill the objectives and the result of this analysis had been illustrated in the table no 3 . The result found that only for the three plants had 
death affect against tea thrips when used $1 \%$ of concentration. But for these three plants mean value ranged from .33 to 1.67 which was not significant compared to total tea thrips. For the concentration of $10 \%$ and $15 \%$, the death effect of thrips was found to be maximum. From the standard deviation value, it was found that there was significant death affect relation between the plant pair of Glycosmis arborea versus Justicia gendarussa for the maximum concentration of $10 \%$. For the maximum concentration of $15 \%$, this relation was found between the plants Ipomoea hederaceaa versus Lantana camara, and Ipomoea hederaceaa and Glycosmis arborea. The result signifies that Ipomoea crassicaulis has the minimum CV value (5.44) and Lantana camara (6.69), Ipomoea hederaceaa (7.91), Glycosmis arborea (8.70), Justicia gendarussa 24.84) respectively. So, Ipomoea crassicaulis extracts was found to be the most promising plant depending on the maximum plant extracts concentration (15\%) to death affect and rest of the plants respectively based on coefficient of variance value.

Table 3. Post hoc test result of different plants extracts to control tea thrips based on extracts concentrations

\begin{tabular}{ccccccc}
\hline & \multicolumn{5}{c}{ Maximum concentration (up to 15\%) to death affect } \\
\cline { 2 - 7 } Plants name & $1 \%$ & $5 \%$ & $10 \%$ & \multicolumn{2}{c}{$15 \%$} & \\
\cline { 2 - 7 } & Mean \pm SD & Mean \pm SD & Mean \pm SD & Mean \pm SD & CV & Ranking \\
\cline { 2 - 7 } & $0.33 \pm 0.58 \mathrm{a}$ & $6.33 \pm 0.58 \mathrm{a}$ & $9.00 \pm 0.00 \mathrm{a}$ & $10.67 \pm 0.58 \mathrm{a}$ & 5.44 & 1 \\
\hline Ipomoea crassicaulis & $0.00 \pm 0.00$ & $0.00 \pm 0.00$ & $0.00 \pm 0.00$ & $7.33 \pm 0.58 \mathrm{bc}$ & 7.91 & 3 \\
Ipomoea hederaceaa & $1.67 \pm 0.58 \mathrm{~b}$ & $3.33 \pm 0.58 \mathrm{~b}$ & $7.33 \pm 0.58 \mathrm{~b}$ & $8.67 \pm 0.58 \mathrm{~b}$ & 6.69 & 2 \\
Lantana camara & $0.00 \pm 0.00$ & $0.33 \pm 0.58 \mathrm{c}$ & $2.33 \pm 0.58 \mathrm{c}$ & $6.67 \pm 0.58 \mathrm{c}$ & 8.70 & 4 \\
Glycosmis arborea & $0.33 \pm 0.58 \mathrm{a}$ & $0.67 \pm 1.16 \mathrm{c}$ & $1.67 \pm 1.16 \mathrm{c}$ & $4.67 \pm 1.16 \mathrm{~d}$ & 24.84 & 5 \\
Justicia gendarussa & $0.47 \pm 0.74$ & $2.13 \pm 2.56$ & $4.07 \pm 3.63$ & $7.60 \pm 2.17$ & 28.55 & - \\
\hline Total & & & & & & \\
\hline
\end{tabular}

Means within a column followed by the same letters are not statistically significantly different based on Tukey's Post Hoc test (at $p=0.05$ )

\section{Conclusion}

The study was conducted to find out the efficacy of individual plants extracts against tea thrips based on different concentration and time for selecting the best natural pesticides. According to all the results obtained 
in the study, it could be concluded that Ipomoea crassicaulis and Lantana camara are the most promising of all the experimented plants extracts based on both time and concentration. So, these medicinally important plants are the significant natural source that can be used to control the thrips attack on tea leaves. Further biochemical investigations are in progress for purification and characterization of bioactive molecule present in the above described medicinal plants.

\section{References}

Ahmed M (2005). Tea Pest Management. Evergreen Printing and Packaging. Dhaka, Bangladesh, pp. 118.

Antony B, Sinu PA and Rahman A (2012). Looper caterpillar invasion in North-East Indian tea agro-ecosystem: Change of weather and habitat loss may be possible causes. Journal of Tea Science Research, 2(1): 1-5.

Ashrafuzzaman M, Halim MA, Ismail MR, Shahullah SM and Hossain MA (2011). Effect of plastic mulch on the growth and yeild of chilli (Capsicum annuum L.). An International Journal of Brazilian Archives of Biology and Technology, 54(2): 321-330.

Borthakur M, Rahman A and Sarmah S (2010). Pest management in tea in North East India. Bul. UPASI Tea Res. Found. 55: 10-18.

Grayer RJ and Harborne JB (1994). A Survey of antifungal compounds from higher plants 1982-1993. Phytochemistry, 37: $19-42$.

Hagstrum DW and Athanassiou CG (2019). Improving stored product insect pest management: from theory to practice. Insects, 10 (332): 1-7.

Hazarika LK, Bhuyan M and Hazarika BN (2009). Insect pests of tea and their management. Annual Review of Entomology, 54: 267-284.

Kim Y, Lee S, Yu Y and Han S (2003). An edible alginate micro-capsulation of entomopathogenic nematode, Steinernema carocapsae, Korean Journal of Applied Entomopathogenic, 42: 145-152.

Liu S, Li Z, Sui Y, Schaefer DA, Alele PO, Chen JC and Yang X (2015). Spider foraging strategies dominate pest suppression in organic tea plantations. Journal of BioControl, pp. 1-8.

Mamun MSA, Hoque MM, Ahmed M, Akandha MYH and Paul SK (2016). Evaluation of some potential miticides against red spider mite infesting tea in Bangladesh. Tea Journal of Bangladesh, 45: 52-64.

Noori MN, Mamun MSA and Ali M, (2016). Impact of climate change on tea production in Bangladesh: A case study on Bilashcherra Experimental Farm, Tea Journal of Bangladesh, 45: 24-34.

Paul SK, Ahmed M, Mamun MSA and Alam MJ (2017). Diversity of insect, mite and nematode species in tea ecosystem of Bangladesh. Journal of Biodiversity Conservation and Bioreourses Management, 3(1): 31-44

Sana DL (1989). Tea Science. Ashrafia Boi Ghar, Dhaka, Bangladesh, pp.120-197.

Zhou Q, Cheng X, Wang S, Liu S and Wei C (2019). Imidacloprid on the release of C6 green leaf volatiles in tea plants (Camellia sinensis). Scientific Reports, 625: 1-6. 
